ISSN 0258-7122 (Print), 2408-8293 (Online)

Bangladesh J. Agril. Res. 41(3): 433-439, September 2016

\title{
GENETIC DIVERGENCE IN EGGPLANT (Solanum melongena L.) GENOTYPES
}

\author{
M. R. KARIM ${ }^{1}$, M. M. RAHMAN ${ }^{2}$ AND A. K. M. QUAMRUZZAMAN ${ }^{3}$
}

\begin{abstract}
Multivariate analysis of twenty six genotypes of eggplant were done to estimate the genetic diversity and to select the potential parents for a successful hybridization program. As per PCA, $\mathrm{D}^{2}$ and cluster analysis, the genotypes were grouped into five clusters. The highest inter-cluster distance was between Cluster II and Cluster III (37.82) and the lowest between Cluster I and Cluster III (4.39). Cluster III showed the maximum intra-cluster distance (1.58), whereas Cluster II showed the lowest intra-cluster distance (0.48). Considering the magnitude of genetic distance and agronomic performance, the genotypes SM 208 and SM 209 from Cluster II and SM 201, SM 218 and SM 227 from Cluster III might be suitable for efficient hybridization program. On the other hand the genotypes of Cluster I (SM 206, SM 210, SM 211, SM 212, SM 213, SM 215, SM 216, SM 217, SM 221, SM 224, SM 225 and SM 226) possess all the superior characters in respect of yield and yield related component. Thus the genotypes SM 206, SM 216, SM 217, SM 224 and SM 225 from this Cluster could be selected to develop high yielding eggplant varieties.
\end{abstract}

Keywords: Eggplant, $\mathrm{D}^{2}$, Genetic diversity, Hybridization, Multivariate analysis, PCA.

\section{Introduction}

Eggplant (Solanum melongena L.) is one of the most important commercial vegetable crops in the world, especially in the tropics and subtropics. Eggplant belongs to the family Solanaceae and is mainly self-pollinated crop (Bose et al., 2003).

Various forms, colors and shapes of eggplant are found throughout Southeast Asia, suggesting that this area is an important center of variation and possibly of origin. Vavilov (1928) suggested that its center of origin was in the Indo-Burma region. It originated in India but has a secondary center of variation in China. In China, eggplant has been known for the last 1,500 years. It is extensively grown in Bangladesh, India, Pakistan, Nepal, China, Japan and the Philippines. Batugal (2013) stated genetic diversity as a major factor that determines yield security in future.

\footnotetext{
${ }^{1}$ Scientific Officer, Horticulture Research Centre (HRC), Bangladesh Agricultural Research Institute (BARI), Gazipur 1701, ${ }^{2}$ Professor, Department of Horticulture, Bangabandhu Sheikh Mujibur Rahman Agricultural University (BSMRAU), Gazipur $1706,{ }^{3}$ Senior Scientific Officer, HRC, BARI, Gazipur 1701,Bangladesh.
} 
A new variety can be developed from an assembled diverse genetic stock of any crop. The quantification of genetic divergence through biometrical procedures has made it possible to choose genetically diverse parents for a successful hybridization program (Uddin et al., 2014). Moreover, evaluation of genetic diversity is important to know the source of genes for a particular trait within the available germplasm (Amin et al., 2014).

Multivariate analysis is a useful tool to quantify the degree of divergence between the biological population at genotypic level and to assess the relative contribution of different components to the total divergence both inter and intra cluster levels (Ivy et al., 2007; Quamruzzaman et al., 2009; Amin et al., 2014 and Nalla et al., 2014).

Considering the above facts, the present study was under taken to estimate the genetic diversity of selected eggplant genotypes and to select effective parents for future hybridization program.

\section{Materials and Method}

The research work was conducted at the Olericulture division of Horticulture Research Centre (HRC), Bangladesh Agricultural Research Institute (BARI), Gazipur during the period from 14 August 2012 to the last week of February 2013. A total of 26 eggplant genotypes were collected by Olericulture division of Horticulture Research Centre (HRC) of Bangladesh Agricultural Research Institute (BARI), Gazipur, during 2010-2011 which were used in this study. Among 26 genotypes, 22 were collected from abroad (SM 201 from Brazil; SM 202 from Israel; SM 206-210, SM 215-216, SM 220-222, SM 225 and SM 226 from India; SM 211-212, SM 219, SM 223-224 and SM 227 from Thailand; SM 213 from Italy and SM 218 from Netherlands) and 4 (SM 203-204, SM 217 and BARI released Hybrid Tarapuri variety) from local source.

The experiment was laid out in Randomized Complete Block Design with three replications. Each replication contained 26 genotypes and the genotypes were randomly distributed to unit plot within each block. Multivariate analysis was done by computer using GENSTAT 5 (Fifth Edition Beta) and Microsoft Excel Professional Plus 2010 software through four techniques viz., Principal Component Analysis (PCA), Principal Coordinate Analysis (PCO), Cluster Analysis (CLA) and Canonical Variate Analysis (CVA).

\section{Results and Discussion}

\section{Principal component analysis (PCA)}

Principal components were computed from the correlation matrix and genotype scores obtained from first components and succeeding components with latent roots 
greater than the unity. Contributions of the different morphological characters towards divergence were discussed from the latent vectors of the first two principal components. The principal component analysis yielded eigen values of each principal component axes with the first axes totally accounting for the variation among the genotypes for days to $50 \%$ plant flowering is 48.22 , while two of these with eigen values above unity accounted for $63.15 \%$ (Table 1).The first three principal axes accounted for $76.59 \%$ of the total variation among the 10 characters describing 26 eggplant genotypes. Alam et al. (2011) found $78.13 \%$ total variation for the first three eigen values for three principal coordination axes from the principal component analysis of 22 lentil genotypes. The minimum acceptable value of cumulative eigen value of the principal component for coconut is $75 \%$ (Emannuel, 2002).

Table 1. Eigen values and percent of variation in respect of 10 characters in 26 eggplant genotypes

\begin{tabular}{l|l|c|c|c}
\hline $\begin{array}{c}\text { Principal } \\
\text { component } \\
\text { Axis }\end{array}$ & \multicolumn{1}{c|}{$\begin{array}{c}\text { Principal component } \\
\text { characters }\end{array}$} & $\begin{array}{c}\text { Eigen } \\
\text { values }\end{array}$ & $\begin{array}{c}\text { Percentage of total } \\
\text { variation } \\
\text { accounted for }\end{array}$ & $\begin{array}{c}\text { Cumulative } \\
(\%)\end{array}$ \\
\hline I & $\begin{array}{l}\text { Days to 50\% plant } \\
\text { flowering }\end{array}$ & 4.823 & 48.22 & 48.22 \\
II & Flower per inflorescence & 1.493 & 14.93 & 63.15 \\
III & Fruit length (cm) & 1.344 & 13.44 & 76.59 \\
IV & Fruit breadth (cm) & 0.772 & 7.72 & 84.31 \\
V & Fruits per infructescence & 0.545 & 5.45 & 89.76 \\
VI & Fruits per plant & 0.544 & 5.44 & 95.20 \\
VII & Fruit weight (g) & 0.315 & 3.15 & 98.35 \\
VIII & Fruit yield (t/ha) & 0.114 & 1.14 & 99.49 \\
IX & Seeds per fruit & 0.050 & 0.50 & 99.99 \\
X & 100 seeds weight $(\mathrm{g})$ & 0.0005 & 0.01 & 100.00 \\
\hline
\end{tabular}

\section{Construction of scatter diagram}

Depending on the values of principal component scores 2 and 1 obtained from the principal component analysis, a two dimensional scatter diagram $\left(Z_{1}-Z_{2}\right)$ using component score 1 as $\mathrm{X}$-axis and component score 2 as $\mathrm{Y}$-axis was constructed. The position of the genotypes in the scatter diagram was apparently distributed into five groups, which indicated that there existed considerable diversity among the genotypes (Figure 1). 


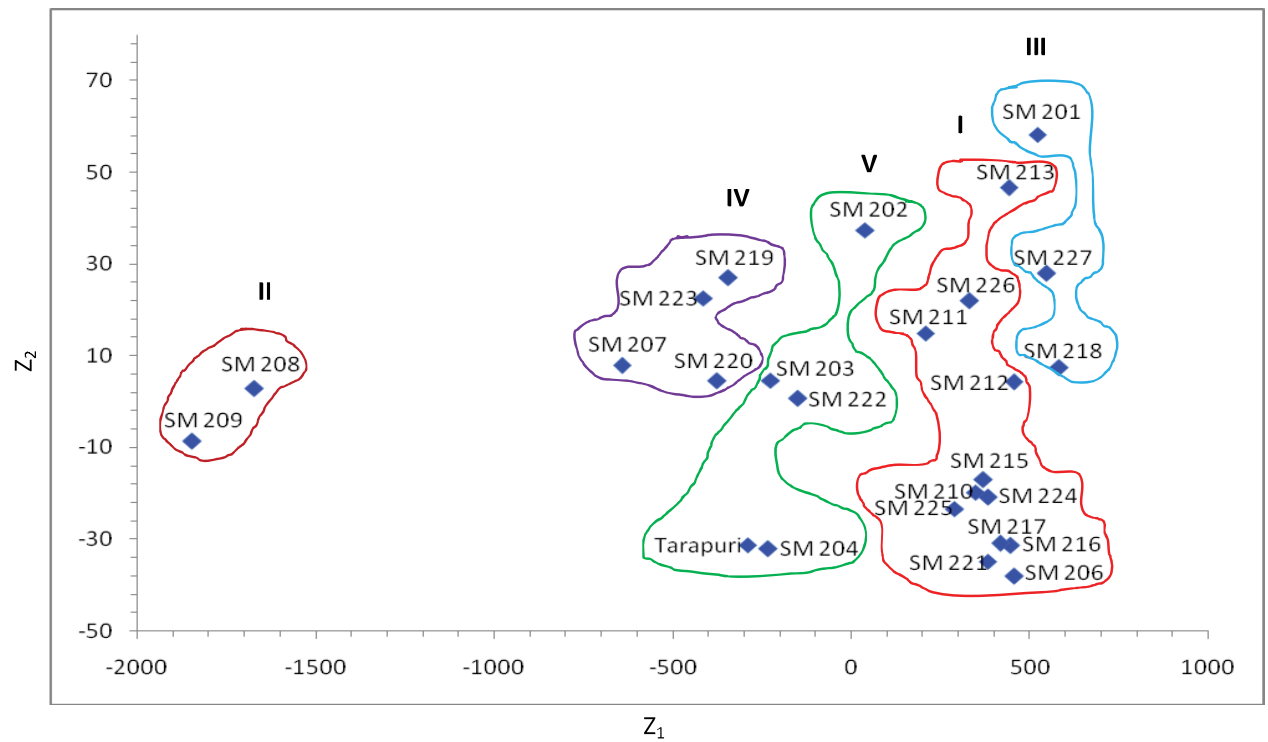

Figure 1. Scatter distribution of 26 eggplant genotypes based on their principal component scores superimposed with clustering.

\section{Cluster analysis (CLA)}

Cluster analysis is used to arrange the genotypes into more or less homogeneous groups and it confirmed the clustering pattern of principle component analysis. By using covariance matrix with the application of non- hierarchical clustering, the 26 eggplant genotypes were grouped into 5 (five) clusters. Singh et al. (2012) also found five different clusters from the cluster analysis of 36 pecan genotypes on the basis of their genetic distinctness. Compositions of different clusters with their corresponding genotype(s) in each cluster were presented in Table 2.

Table 2. Distribution of 26 eggplant genotypes in five different clusters with their place of collection

\begin{tabular}{llll}
\hline Cluster No. & Genotypes & Genotypes including sources of collection \\
\hline I & 12 & SM 206, SM 210, SM 211, SM 212, SM 213, SM 215, SM \\
& & 216, SM 217, SM 221, SM 224, SM 225 and SM 226 \\
II & 2 & SM 208 and SM 209 \\
III & 3 & SM 201, SM 218 and SM 227 \\
IV & 4 & SM 207, SM 219, SM 220 and SM 223 \\
V & 5 & SM 202, SM 203, SM 204, SM 222 and Tarapuri \\
\hline
\end{tabular}

\section{Principal coordinate analysis (PCO)}

Principal coordinate analysis was performed on auxiliary of principal component analysis. Inter genotypic distances obtained from Principal Coordinate Analysis 
showed that the highest distance (3.931) was observed between the genotypes SM 209 and SM 218 followed by SM 208 and SM 218 (3.930), SM 209 and SM 227 (3.511), SM 208 and SM 227 (3.450) and the lowest distance was observed between the genotypes SM 206 and SM $216(0.298)$ followed by SM 217 and SM 221 (0.399), SM 211 and SM 226 (0.454) and SM 215 and SM 224 (0.456) (Table 3). From the principal coordinate analysis of 22 Lentil genotypes Alam et al. (2011) observed that the highest distance between two genotypes was 0.9365 where as the lowest distance was 0.0595 which indicate the presence of moderate variability among the genotypes. By using these distances from distance matrix intra and inter-cluster distances were calculated (Table 4).

Table 3. Ten of each higher and lower inter-genotypic distance $\left(\mathrm{D}^{2}\right)$ between pair of eggplant genotypes

\begin{tabular}{c|c|c|c}
\hline 10 higher $D^{2}$ values & Genotypes combination & 10 lower $D^{2}$ values & $\begin{array}{c}\text { Genotypes } \\
\text { combination }\end{array}$ \\
\hline 3.931 & SM 209 and SM 218 & 0.298 & SM 206 and SM 216 \\
3.930 & SM 208 and SM 218 & 0.399 & SM 217 and SM 221 \\
3.511 & SM 209 and SM 227 & 0.454 & SM 211 and SM 226 \\
3.450 & SM 208 and SM 227 & 0.456 & SM 215 and SM 224 \\
3.317 & SM 207 and SM 218 & 0.482 & SM 208 and SM 209 \\
3.257 & SM 201 and SM 209 & 0.546 & SM 206 and SM 221 \\
3.137 & SM 218 and SM 223 & 0.570 & SM 206 and SM 217 \\
3.120 & SM 218 and SM 219 & 0.584 & SM 210 and SM 215 \\
3.112 & SM 201 and SM 208 & 0.590 & SM 216 and SM 221 \\
3.065 & SM 206 and SM 208 & 0.593 & SM 216 and SM 217 \\
\hline
\end{tabular}

\section{Canonical variate analysis (CVA)}

Canonical variate analysis was used to compute the inter-cluster Mahalanobis' $\mathrm{D}^{2}$ values. The Table 4 indicates the intra and inter-cluster distance $\left(\mathrm{D}^{2}\right)$ values. The inter-cluster distances were higher than the intra-cluster distances suggesting wider genetic diversity among the genotypes of different groups (Table 4). Results indicated that the highest inter- cluster distance was observed between Cluster II and Cluster III (37.82) followed by between Cluster I and Cluster II (34.20), Cluster II and Cluster V (26.40) and finally Cluster II and Cluster IV (21.22) (Table 4). The lowest inter-cluster distance was observed between the Cluster I and Cluster III (4.39), followed by Cluster IV and Cluster V (5.51), Cluster I and Cluster V (8.35) and finally Cluster III and Cluster V (11.46) (Table 4). So, genotypes from the Cluster II and Cluster III if involved in hybridization might produce a wide spectrum of segregating population, as genetic variation was very distinct among these groups. According to Singh et al. (2012) these 
genotypes can also be utilized for transfer of useful traits in the commercial cultivars.

Table 4. Average intra (Bold) and inter cluster distances $\left(D^{2}\right)$ for 26 genotypes of eggplant

\begin{tabular}{cccccc}
\hline Cluster & I & II & III & IV & V \\
\hline I & $\mathbf{1 . 0 8}$ & 34.20 & 4.39 & 12.99 & 8.35 \\
II & & $\mathbf{0 . 4 8}$ & 37.82 & 21.22 & 26.40 \\
III & & & $\mathbf{1 . 5 8}$ & 16.65 & 11.46 \\
IV & & & & $\mathbf{0 . 8 3}$ & 5.51 \\
V & & & & & $\mathbf{1 . 2 1}$ \\
\hline
\end{tabular}

Contribution of characters towards divergence of the genotypes is presented in Table 5. The vector-I $\left(Z_{1}\right)$ obtained from PCA, the important characters responsible for genetic divergence in the axis of the differentiation were 100 seeds weight $(\mathrm{g})$ (3.6482), fruits per infructescence (1.5199), fruit yield ( $\mathrm{t} / \mathrm{ha})$ $(0.1935)$ and flower per inflorescence $(0.1398)$. In vector-II $\left(Z_{2}\right), 100$ seeds weight $(\mathrm{g})(5.8597)$, fruits per infructescence $(1.8438)$, fruit yield $(\mathrm{t} / \mathrm{ha})(0.4458)$ and days to $50 \%$ plant flowering $(0.0271)$ were the important characters responsible for genetic divergence. The role of fruits per infructescence, fruit yield ( $\mathrm{t} / \mathrm{ha}$ ) and 100 seeds weight $(\mathrm{g})$ in both the vectors were important components for genetic divergence in these materials. From the canonical variate analysis of 22 Lentil genotypes Alam et al. (2011) also noticed three characters such as days to maturity, plant height and pods per plant have positive values in both the vectors which indicate the highest contribution of these characters towards the divergence.

Table 5. Latent vectors for ten characters of 26 eggplant genotypes

\begin{tabular}{lcc}
\hline Characters & Vector 1 & Vector 2 \\
\hline Days to 50\% plant flowering & -0.0180 & 0.0271 \\
Flower per inflorescence & 0.1398 & -0.5484 \\
Fruit length $(\mathrm{cm})$ & 0.0297 & -0.0927 \\
Fruit breadth $(\mathrm{cm})$ & -0.1151 & -1.0795 \\
Fruits per inflorescence & 1.5199 & 1.8438 \\
Fruits per plant & -0.0054 & -0.6222 \\
Fruit weight $(\mathrm{g})$ & -0.1600 & -0.1553 \\
Fruit yield (t/ha) & 0.1935 & 0.4458 \\
Seeds per fruit & 0.0169 & 0.0016 \\
100 seeds weight $(\mathrm{g})$ & 3.6482 & 5.8597 \\
\hline
\end{tabular}




\section{Conclusion}

Considering the magnitude of genetic distance and agronomic performance, the genotypes SM 208 and SM 209 from Cluster II and SM 201, SM 218 and SM 227 from Cluster III would be suitable for efficient hybridization program.

\section{References}

Alam, A.K.M.M., R. Podder and A. Sarker. 2011. Estimation of genetic diversity in lentil germplasm. Agrivita J. Agril. Sci. 33(2): 103-110.

Amin, M.F., M. Hasan, N.C.D. Barma, M.G. Rasul and M.M. Rahman. 2014. Genetic diversity analysis in spring wheat (Triricum aestivum L.). Bangladesh J. Agril. Res. 39(2): 189-196.

Batugal, P.A. 2013. The Role of International Cooperation in the Development of Biotechnology in Coconut. In: Current Advances in Coconut Biotechnology. C. Oropeza, J.L. Verdeli, G.R. Ashburner, R. Cardena and J.M. Santamaria [eds.]. Springer-Science+Business Media, B.V. P. 21.

Bose, T.K., J. Kabir, T.K. Maity, V.A. Parthasarthy and M.G. Som. 2003. Vegetable Crops. Third Revised Edition. Volume 1. Naya Udyog, Kolkata, India. Pp. 1-700.

Emannuel, E.E. 2002. Morphometric traits and DNA profiles of three generations of selected coconut genotypes. M.S. Thesis. Plant Genetic Resources Conservation and Management, University of Philippines (UPLB), Los Baños, Laguna, Philippines, Pp. 1-89.

Ivy, N.A., M. Shalim Uddin, R. Sultana and M.M. Masud. 2007. Genetic divergence in maize (Zea mays L.). Bangladesh J. Pl. Breed. Genet. 20(1) : 53-56.

Nalla, M.K., M.K. Rana, S.J. Singh, A.K. Sinha, P.K. Reddy and P.P. Mohapatra. 2014. Assessment of genetic diversity through $\mathrm{D}^{2}$ analysis in tomato (Solanum lycopersicon L.). International Journal of Innovation and Applied Studies. 6(3): 431438.

Quamruzzaman, A.K.M., M.A. Rashid, S. Ahmad and M. Moniruzzaman. 2009. Genetic divergence analysis in eggplant (Solanum melongena L.). Bangladesh J. Agril. Res. 34(4): 705-712.

Singh, D., R.K. Kaler, K. Kumar and N. Sharma. 2012. Genetic diversity and character association in different seedling pecan (Carya illinoensis) genotypes. Indian J. Agril. Sci. 82(11): 911-915.

Uddin, M.S., M.M. Rahman, M.M. Hossain and M.A.K. Mian. 2014. Genetic diversity in eggplant genotypes for heat tolerance. SAARC J. Agri. 12(2): 25-39.

Vavilov, N. 1928. Proc. Fifth International Congress of Genetics. New York, Pp. 342369. 